\title{
A ABORDAGEM DA MOBILIZAÇÃO DO DIREITO ENTRE A CRÍTICA NECESSÁRIA E A CRÍTICA POSSÍVEL
}

Celly Cook Inatomi

é doutora em Ciência Política pela Universidade de Campinas (Unicamp)

E-mail:celoca05@yahoo.com.br

Orcid: 0000-0002-7473-466X

http://dx.doi.org/10.1590/0102-101119/108

Qual é a responsabilidade das análises sociopolíticas do direito com as políticas de direitos, especialmente em períodos de crise política? Devem elas fazer a crítica necessária ao direito liberal mantendo seus estudos desvinculados das políticas de direitos estatais, de forma a manter a autonomia da pesquisa acadêmica e, assim, explorar todo e qualquer ponto problemático do direito e da atuação do Estado? Ou devem elas fazer a crítica possível, trabalhando em conjunto com as políticas estatais de forma a dar fim às chamadas "injustiças intoleráveis" que acontecem especialmente em períodos de crise política? Ou, ainda, devem elas ser teoricamente profundas ao mesmo tempo sem esquecer seu papel social? É possível esse tipo de articulação ou estaríamos lidando, infelizmente, com o fim da era dos direitos, em que as possibilidades de interferência nas políticas estatais são verdadeiras joias preciosas em meio ao crescimento do conservadorismo e do autoritarismo em diversos cantos do mundo?

Tratamos grande parte dessas questões em trabalho anterior, quando estudamos uma das influências centrais 
da abordagem da mobilização do direito, o movimento da Law \& Society Association (L\&S), analisando sua formação, objetivos, ligações com as políticas estatais e desenvolvimentos recentes (Inatomi, 2018). Vimos que, pelo menos desde os anos 1990, alguns estudiosos vêm fazendo uma espécie de revisionismo da sua produção desde os anos 1960, mostrando-se incomodados ora com a estagnação teórica das pesquisas até então desenvolvidas, ora com a inércia política de seus trabalhos frente aos problemas sociais. Em qualquer um dos casos, no entanto, a chamada "virada cultural" e "interpretativista" dos anos 1980 aparece como cerne de todo o debate: ora tida como responsável pelas insuficiências teóricas e políticas; ora como apenas um resultado da conjuntura política; e, em algumas análises, como uma abordagem importante por alterar as lentes de análise do direito.

Por beber praticamente das mesmas fontes teóricas que a L\&S, especialmente do culturalismo e do interpretativismo, 102 a abordagem da mobilização do direito acabou sendo alvo do mesmo revisionismo, de modo que falar das críticas ao culturalismo é semelhante a falar das críticas à mobilização do direito. Michael McCann (2006), inclusive, autor central da abordagem, já reconheceu algumas das limitações apontadas pelos revisionistas, falando sobre a necessidade de um olhar mais cuidadoso para as questões trazidas pelas grandes teorias, a fim de pensar criticamente o direito e suas mobilizações.

O que percebemos, no entanto, é a permanência do culturalismo e do interpretativismo, bem como do estudo exploratório, e não explicativo, para insistir na ideia do direito como algo constitutivo, mas que agora se alia mais enfaticamente a preocupações como coerção, dominação, violência e hegemonia. O resultado, como não poderia deixar de ser, é uma resposta arrazoada, que coloca a crítica tanto como necessária quanto possível, reconhecendo generosamente o valor dos estudos culturalistas, mas agora em conjunto com estudos mais deterministas do direito. 
Diante disso, o objetivo deste artigo é recolocar o debate sobre a importância e o impacto do culturalismo, resgatando as críticas que lhe foram direcionadas para em seguida trabalhar a sua definição de forma abrangente e generosa. O intuito é repensar a capacidade crítica (teórica e política) do culturalismo em si, o que acaba nos fazendo repensar também a capacidade crítica da própria mobilização do direito, que se nutre dele. Em tempos em que a disputa pelo significado dos direitos perpassa não apenas os mecanismos institucionais, mas adentra as esferas comuns da sociedade, como escolas, espetáculos culturais, filmes e o próprio cotidiano, acreditamos que a crítica ao direito feita pelo culturalismo ainda tem coisas muito importantes a nos dizer, e deve, portanto, ser estudada e debatida.

\section{Três visões sobre a "virada cultural"}

Quando os estudiosos da Law \& Society Association revisam sua produção desde os anos 1960, a "virada cultural" é lida sob três visões principais. Uma primeira, bastante presente entre os estudiosos, a considera uma das principais vilãs do descrédito em que as ciências sociais caíram a partir do final dos anos 1970 e início dos anos 1980, acusando-a de ser uma das razões da falência teórica e política do movimento (Abel, 2010; Calavita, 2002, 2010; Friedman, 1986; Handler, 1992; Liu, 2015; Munger, 2001; Rosenberg, 1996). A segunda diz que tal virada nada mais foi que resultado da própria conjuntura política, em que a aproximação do Estado com o movimento da Law \& Economics colocou para escanteio as pesquisas em ciências sociais (Abel, 2010; Garth e Sterling, 1998), possibilitando o livre desenvolvimento destas. A terceira, por fim, diz que a virada cultural deve ser vista de modo menos positivista e menos pragmático, no sentido de entender que sua perspectiva do direito permitiu um olhar mais atento para outros fatores que costumamos não perceber - como o "direito na vida cotidiana" - 
e que têm impactos importantes sobre a relação entre direito e sociedade (Ewick, 1992; Ewick e Silbey, 1999; Levine, 1990).

\section{A "virada cultural" como causa da falência teórica e política}

Especificamente no que tange à falência teórica, os revisionistas argumentam que esta resultou, em primeiro lugar, da própria opção feita pelos primeiros trabalhos da L\&S (Friedman, 1986; Salvesberg et al., 2016). Voltados sobretudo para a questão tão premente dos direitos civis durante os anos 1960, para as reformas no sistema de justiça e na esfera criminal, bem como para a questão da pobreza, esses primeiros trabalhos participaram ativamente das políticas de direitos do Estado, abrindo mão de pensar as grandes questões teóricas que envolvem o direito liberal. $\mathrm{O}$ retrato mais claro disso é o baixo número de artigos voltados para a discussão teórica na revista Law E Society Review (Abel, 2010; Liu, 2015; Savelsberg et al., 2016). O mainstream do movimento estava voltado a uma crítica possível do direito, qual seja, a de apontar o vão existente entre o direito nos livros e na realidade, recuperando questões próprias dos realistas jurídicos (Abel, 2010; Schwartz, 1968). Tudo para conseguir influenciar as políticas estatais e alterar o quadro de extrema segregação racial e de injustiças sociais generalizadas. ${ }^{1}$

Em segundo lugar, os revisionistas apontam que a falência teórica também se deu, em grande medida, por causa

\footnotetext{
1 Ver, por exemplo, a primeira edição da revista, em que a L\&S se propõe a empreender uma agenda política e social absolutamente prática, voltando-se para a intervenção em problemas reais da população pobre. Os textos tratam, ainda, das necessidades jurídicas dessa mesma população, para repensar a qualidade dos serviços jurídicos que lhes eram fornecidos. A quarta edição da revista foi dedicada a Arnold Marshall Rose, que havia colaborado com Gunnar Myrdal (1944) em seu livro An American dilemma: the negro problem and modern democracy, e também tinha sido citado pela histórica decisão da Suprema Corte, Brown v. Board of Education, em razão de seus trabalhos sobre a situação da população negra nos Estados Unidos. Além desses exemplos, uma edição especial da revista lidou com a integração racial nas escolas, acompanhando a implementação de políticas do Civil Rights Act de 1964, a pedido do governo federal.
} 
da "virada cultural" e "interpretativista" dos estudos, que, uma vez abandonados pelo Estado (a partir de meados dos anos 1970), ao invés de sedimentarem a necessária crítica ao direito liberal, passaram a considerar diversas expressões como sendo expressões jurídicas, que mereciam ser estudadas em profundidade. Era a ideia do law in everyday life. Segundo alguns revisionistas, esses estudos levaram o direito a tal grau de relativismo e de especificidade que a síntese teórica se tornou cada vez mais difícil e, por vezes, até mesmo rechaçada (Handler, 1992).

Por outro lado, quando se fala em "deserto político", aponta-se a necessidade de retomar os objetivos realistas do movimento L\&S nos anos 1960: lutar por políticas de direitos e evitar "injustiças intoleráveis", recuperando a ideia de crítica possível (Calavita, 2002, 2010). Embora tenha expandido a análise em diversos contextos e locais, a virada cultural e interpretativista dificultou a articulação em torno das grandes políticas de direitos ao se abstrair em seus estudos e especificar demasiadamente seu objeto. Em contextos de extrema violação de direitos ou de crise política acentuada, ver a expressão do direito em qualquer manifestação particular, como no revirar do olho de um réu dentro de um tribunal, não significa, como se queria, uma reconstituição do direito oficial e das instituições jurídicas, mas sim a única e possível expressão de desprezo por uma Justiça injusta, que condena por razões pautadas no racismo, na xenofobia, na homofobia ou em outro tipo de discriminação própria dos períodos de crise dos direitos. $\mathrm{E}$ a atitude de desprezo pelo direito oficial não representa nada além de uma simbologia sem efetividade.

Portanto, o quadro que grande parte dos revisionistas pintam - estejam eles querendo recuperar a teoria política ou a força política do movimento - é o de que os estudos culturalistas teriam criado uma espécie de "jardim encantado" em que as manifestações de contraditoriedade ao 
direito oficial são mais valorizadas do que as demonstrações de dominação, coerção, violência ou hegemonia através do direito e suas instituições.

\section{A "virada cultural" como resultado da conjuntura política}

Outros estudiosos sustentam que a virada cultural nos estudos sociojurídicos seria o resultado inevitável da conjuntura política específica de meados dos anos 1970 e início dos anos 1980. Com a crise nas políticas de bem-estar social, o Estado passa a se retirar cada vez mais do cenário, deixando os estudos das ciências sociais de lado (Garth e Sterling, 1998; Savelsberg et al., 2016). É neste momento que surge o movimento dos critical legal studies, cujos teóricos passam a cobrar a crítica às políticas liberais de direitos do Estado.

Embora os estudos culturalistas tenham sido influenciados, logo em seu início, pelas necessárias críticas dos critical legal studies, os revisionistas apontam o que outros estudiosos 106 anteriormente citados já apontaram: tais críticas acabam se tornando um aglomerado de estudos de caso que veem o direito em todos os lugares, menos no direito oficial. Por não ver saída em políticas de direito estatal, os teóricos teriam passado a percorrer toda e qualquer manifestação que entendiam como de oposição e, mais além, de construção de outras ordens jurídicas. Isso, segundo os críticos - como já exposto na questão da falência teórica e política - não ajudaria a pensar o problema do direito em tempos de crise, quando temas como dominação, hegemonia e violência institucional são trazidos à baila.

Contudo, não se trata de culpar uma determinada abordagem pela crise teórica e política dos estudos, mas, em tempos de crise, repensar as questões levantadas inicialmente por ela de acordo com a conjuntura atual, a fim de que os movimentos em torno dos direitos tenham a real noção de efetividade e transformação social. Nesse sentido, a crítica da dominação exercida pelo direito é importante especialmente nos dias de hoje. 
Pensando como esses revisionistas, poderíamos inclusive nos perguntar: ver hoje o retorno de discussões sobre a garantia de direitos civis, bem como a falência das políticas sociais e os constantes ataques a elas e aos direitos mais básicos da população, não seria admitir que os críticos do direito liberal tinham razão? Em outras palavras, não seria admitir que a saída não está no direito liberal? Não seria essa a constatação de sua falência, de sua "morte", alertando os estudiosos e movimentos de que é necessário outro tipo de mobilização? E que tipo de mobilização seria essa?

\section{A "virada cultural" como uma possível saída}

Um terceiro conjunto de revisionistas aponta que é possível pensar nos pontos positivos da virada cultural e interpretativista justamente por esta estudar o direito em um diapasão diferente do oficial, dando outro tom para os estudos e também, se assim o quiser, para os movimentos sociais (Ewick, 1992; Ewick e Silbey, 1999). Embora à primeira vista pareça um isolamento teórico e político, pensar o direito por outro viés pode ajudar a pensar local ou contextualmente políticas de direitos que formem a consciência jurídica e os movimentos sociais, tendo impacto simbólico e concreto. A especificação auxilia o direcionamento das políticas, permitindo mais profundidade em problemas especialmente de minorias, como mulheres, homossexuais e imigrantes (Levine, 1990).

Além disso, e tendo em vista as investidas que setores conservadores têm feito em diversas frentes de disputa, configurando uma verdadeira "guerra cultural", é mais do que necessário conhecer os trabalhos e as conclusões dos estudos culturalistas, de forma a enxergar os lugares em que as disputas pelo direito e pelos direitos podem se dar e como se dão. As manifestações do direito na vida diária deixam de ser manifestações ocasionais ou sem importância para se tornarem lócus de grandes disputas que perpassam as políticas no Executivo, no Legislativo e no Judiciário. 


\section{Repensando a "virada cultural" e sua importância teórica e política}

Para entender a crítica feita pela mobilização do direito é essencial compreender o que significou a "virada cultural" dos anos 1980, vendo em que medida se distanciou, por um lado, da crítica necessária ao direito liberal, e por outro, da crítica possível para influenciar políticas estatais. Para isso é importante, primeiramente, deixar a visão estereotipada de muitos revisionistas e caminhar em direção a uma análise mais generosa, como a de Fisher, Horwitz e Reed (1993), que consideram de forma muito mais ampla o realismo jurídico, apontando a importância de suas análises críticas e políticas. Em um segundo momento, é igualmente essencial compreender de que forma a mobilização do direito articula o estudo culturalista com abordagens que criticam a dominação e a coerção pelo direito, para ver até onde as pesquisas caminharam na crítica ao direito liberal.

108 Como já comentamos, a virada cultural, em sua versão estereotipada, é tida como um "jardim encantando". Por reconhecerem e estudarem uma grande gama de "ordens jurídicas" paralelas à ordem oficial, os estudiosos culturalistas consideraram toda e qualquer forma de expressão popular e individual vinda "de baixo" como manifestamente importante diante do direito oficial. Segundo os críticos, esse pluralismo jurídico sem limites teria sido o principal responsável pela incapacidade da abordagem culturalista de reconhecer e trabalhar com o caráter coercitivo, violento e hegemônico do direito liberal. O resultado seria uma fraqueza substantiva do campo, que acumula estudos de caso incoerentes e inconclusivos, sem fundamentos, axiomas, ou leis gerais sobre o comportamento jurídico e sem qualquer ciência que embase as pesquisas (Friedman, 1986).

Contudo, quando olhamos com cuidado para os trabalhos culturalistas, especialmente para os estudos desenvolvidos pelo Amherst Seminar durante os anos 1980 
(Sarat e Kearns, 1991, 1992 e 1993), observamos que o estereótipo não é completamente justo. Embora os trabalhos culturalistas não tenham resultado até hoje em nenhuma síntese teórica, como admitido por McCann (2006), o nascimento da abordagem estava umbilicalmente ligado a uma crítica do direito liberal. Tratava-se, no entanto, de uma crítica feita por outra perspectiva, a mesma engendrada uma década depois pelos estudos da mobilização do direito, que: 1) aproximava-se mais propriamente das teses indeterministas dos critical legal studies do que das teses deterministas dos estudos críticos de cunho marxista; 2) tomava emprestada a visão interpretativista de Geertz (1964, 2014 e 2017) sobre a ideologia e o direito, entendendo-os não como máscaras ou mentiras, mas como sistemas culturais que constroem significados e formas de vida; e 3) como consequência, tinha um olhar "de baixo para cima" e procurava estudar temas do direito na vida cotidiana, estudando o entendimento de cidadãos comuns sobre o direito, como já faziam os estudos da Law \& Society desde o seu nascimento. O resultado dessa união de influências foi a visão de que o direito teria um caráter constitutivo.

No que tange à influência dos critical legal studies, Sida Liu (2015) destaca que esse era um diferencial importante do movimento culturalista, que se colocava, ao menos inicialmente, com bastante força na crítica teórica ao direito liberal. Os estudiosos do Amherst Seminar se afastaram da abordagem instrumental dos primeiros estudos da L\&S que frequentemente compartilhavam da ideologia jurídica liberal - para se aproximar dos critical legal studies, que apontavam o caráter indeterminado do direito, defendendo que este podia ser instrumento tanto de hegemonia e de dominação quanto de resistência, como bem mostram, mais tarde, os trabalhos de Sally Engle Merry (1994) e Susan Silbey (2005). Nesses estudos, a questão da desigualdade era colocada e pensada através de um complexo teórico 
que envolvia as teorias críticas de Marx, Foucault e os critical legal studies. E embora esse coração teórico do campo tenha se enfraquecido ao longo do tempo com o deslocamento para o estudo de caso, o movimento culturalista tentou inicialmente construir, através de uma fundação teórica sólida, uma ponte importante entre a teoria social crítica e a pesquisa empírica sobre o direito (Silbey e Sarat, 1987).

Stewart Macaulay (1987) aponta também que a influência da abordagem interpretativista de Geertz foi essencial para os estudos culturalistas. O pensamento de Geertz (1964) permite ver o direito como uma ideologia, mas ideologia pensada enquanto sistema cultural, e não como mentira ou ilusão, como nas teorias marxistas deterministas. O direito, pensado como sistema cultural, é como um processo de construção de significados e de formas de vida que tem impactos diretos na realidade. Ele não é, portanto, somente uma máscara, ou algo negativo, que deve ser 110 banido, mas possui em sua constituição uma ambivalência latente: ele pode definir ou obscurecer categorias sociais; pode estabilizar ou desestabilizar expectativas sociais; pode manter ou minar normas sociais de convivência; e fortalecer ou enfraquecer consensos sociais, assim como pode aliviar ou exacerbar as tensões sociais.

E quando se fala que os estudos culturalistas se voltam para o direito in everyday life, Macaulay (1987) diz que a ideia central da virada cultural é adentrar territórios não explorados, aprofundar o olhar "de baixo para cima" e ver como as pessoas comuns entendem o direito e lidam com ele. $\mathrm{O}$ direito, assim, deixa de ser algo que as pessoas aprendem somente nas faculdades, e passa a ser algo que se aprende no dia a dia, na televisão, nos jogos esportivos, nos noticiários, nas artes, no ambiente de trabalho, na escola, na família etc. O objetivo principal é verificar os diferentes entendimentos e usos do direito vindo desses lócus diversificados, a ponto de conseguir ver formas de resistência e de construção de 
outros modos de saber e de usar o direito. Alguns autores, como Patricia Ewick (1992) e Alan Hunt (1990), chegam a apontar a importância desse tipo de estudo para considerar questões como a da contra-hegemonia de Gramsci, falando da importância dos "pequenos" movimentos como constituidores de uma nova hegemonia.

Estudiosos como Austin Sarat e Thomas Kearns (1991) descrevem essa entrada na vida comum como um passo importante para uma crítica do que está invisível no visível, possibilitando que os estudos impactem concretamente a realidade, ainda que local. Para esses autores, ver o direito no tratamento dado cotidianamente a questões como separação e divórcio, aborto, estupro, assédio sexual, discriminação racial e educação especial, é ver que na vida tida como "corriqueira" ocorrem com frequência grandes violações sem que ninguém as perceba. É na vida diária que gestos políticos importantes sedimentam entendimentos e práticas do direito na sociedade, mas passam batidos pelas grandes teorias críticas. Em outras palavras, os estudos culturalistas se voltam para exemplos da vida rotineira para ver como o direito se torna parte de um mundo tomado como dado, mas que na verdade esconde processos sociais de construção de novos significados e violações constantes. Como em Geertz, o direito passa a ser visto como uma ideologia, e esta como um sistema cultural, dando significado social às relações e seus efeitos constitutivos. $\mathrm{O}$ direito não está distante da vida social, mas em completa fusão com as atividades do viver e do saber.

Christine Harrington e Barbara Yngvesson (1990) reforçam essa ideia ao chamar a atenção para práticas tomadas como dadas, que fazem o direito aparecer apartado das relações, como uma ordem destacada e diferente, sem continuidade com a prática social. As autoras, assim como Sarat e Kearns (1991), apontam a presença do direito no invisível, dizendo, por exemplo, que o conceito de violência 
simbólica, que sugere dominação, é criado e mantido através das relações diárias, o que permite ver como a ideologia é produzida nas relações, por sua vez ideologicamente constituídas. As autoras veem o direito, portanto, em uma variedade de lugares e práticas, apontando que não é somente ao olhar o poder e o direito oficial que conseguimos perceber dominação, violência e hegemonia, mas também interpretando o poder nas práticas diárias e os entendimentos do senso comum esquecidos pelas críticas.

A junção de todas essas preocupações dos estudos culturalistas resulta na recuperação da visão constitutiva do direito, lançada ainda durante os anos 1960 por Stuart A. Scheingold (2004), considerado o fundador da mobilização do direito. A perspectiva constitutiva aponta para a ambivalência do direito, ou seja, para a possibilidade de utilizá-lo tanto como coerção quanto como resistência. Segundo John Brigham (1998), tal perspectiva desafia o idealismo do 112 direito liberal, não havendo que dizer que seus trabalhos se esquivam da tarefa de criticá-lo. A grande questão é que os culturalistas fazem a crítica do direito por outro prisma. Scheingold, responsável por introduzir o trabalho de Geertz sobre ideologia nos estudos sociojurídicos, deu significado simbólico aos usos instrumentais do direito ao ensinar a uma geração de estudiosos que o direito condiciona percepções, estabelece expectativas, fornece padrões de legitimidade e, por isso, tem grande importância para os padrões institucionais da política americana. O "mito dos direitos" americano não é mera ideologia enganadora e mentirosa, mas condiciona comportamentos e entendimentos. Logo, o olhar sobre o direito não deve ser direcionado somente para seus lócus oficiais, mas para a sociedade como um todo.

Após Scheingold, foi aberto o caminho para os estudos constitutivos do direito, que se fortaleceram sobretudo a partir da falência dos estudos intervencionistas da L\&S no final dos anos 1970 e início dos anos 1980, de onde 
resultaram os critical legal studies, os estudos culturalistas e uma série de outros autores adeptos da visão constitutiva do direito, como Karl Klare (1979), Robert Gordon (1984) e Alan Hunt (1990).

Depois deles, como vimos, vários autores apontaram o deserto teórico e empírico da virada cultural e sua visão constitutiva. Ao responder a um desses críticos, Michael W. McCann (1996) levantou considerações e perguntas muito importantes para pensar o valor teórico e político das abordagens culturalistas, inclusive da mobilização do direito. Ele aponta que as críticas geralmente dirigidas a esses trabalhos, como as de Handler (1992), além de possuírem uma visão muito negativa das possibilidades de agência dos sujeitos na sociedade, mal tocam na reorientação fundamental que os estudos culturalistas fazem da questão política. Segundo McCann, tais autores ecoam as velhas críticas deterministas ao direito liberal nos EUA, que não levam em conta o caráter dos novos movimentos sociais. Teóricos como Handler olhariam para os novos movimentos sociais como movimentos do passado, a partir de caraterísticas vagas, que não conseguem abranger questões de gênero, sexo, raça e classe em seu conjunto.

McCann chegará a admitir a falta de capacidade política dos estudos culturalistas no que tange a mudanças sociais de ampla escala, especialmente frente ao declínio das políticas de bem-estar social nos anos 1980. O autor levanta questões importantes, como: devemos voltar a reduzir pessoas concretas a identidades engessadas e mutualmente excludentes de classe, raça ou gênero? A visão culturalista não fornece um entendimento mais realista da hegemonia e um retrato empiricamente mais rico da prática do poder? Ou, como colocou Brigham (1996), a possibilidade de o direito ser usado de diferentes maneiras e por diferentes atores não seria uma conquista histórica dos movimentos sociais ao invés de mera característica do direito liberal? Não teriam 
os autores culturalistas fornecido um quadro mais complexo e sistemático para compreender fatores contextuais, contribuindo de maneira significativa para o entendimento das dinâmicas de poder invisíveis nas visíveis relações do dia a dia? Enfim, não teriam os estudos culturalistas discutido de forma muito mais rica, em detalhes, como ocorrem as relações em torno do direito, sejam elas de transformação, consenso ou dominação?

Anos mais tarde, ao trabalhar com o tema da consciência jurídica, McCann (2006) recupera a questão da capacidade teórica e política das abordagens culturalistas, concluindo que algumas das críticas que vêm sendo feitas desde os anos 1990 não foram ainda respondidas. Diante disso, o autor fala de alguns trabalhos que demonstraram encaminhamentos importantes, como o de Ewick (1992) e Ewick e Silbey (1999), resumindo alguns pontos centrais para aumentar o alcance desses estudos.

114 Uma questão que McCann assinala como problemática é a do enfoque repetido e isolado sobre pessoas comuns e práticas do dia a dia, apontando a importância de expandir a pesquisa para estudar ricos, famosos e membros da elite. Afinal, questiona o autor, os entendimentos e as práticas de atores poderosos não fazem parte da vida comum? Nós não devemos nos preocupar com os diferentes níveis de construção do entendimento e da consciência dos direitos? O rótulo de estudos "de baixo para cima" não deve ser revisado? Essas limitações não impedem estudos comparativos mais amplos? A especificidade dos entendimentos jurídicos de trabalhadores e de grupos minoritários não fica mais clara se estudarmos também os empregadores, os gerentes, os proprietários e outros grupos de poder?

McCann também propõe, como forma de melhorar os estudos culturalistas, a discussão do contexto. De forma geral, ao estudar empiricamente os casos, as abordagens culturalistas tendem a fazer uma discussão randômica 
sobre características superficiais do espaço. Na verdade, diz o autor, poucos estudos desenvolvem de forma explícita pesquisas sistemáticas de elementos inter-relacionados que podem definir a análise contextual adequada. Esforços mais sistemáticos para analisar aspectos-chave do contexto e da situação do sujeito podem ser úteis para entender o sentido empregado pelos indivíduos diante da legalidade e como e por que alguns entendimentos tendem a passar por cima de outros, de modo a avançar o pensamento sobre a constituição dos sujeitos e de sua consciência.

Segundo McCann, um tipo de omissão na análise contextual é a relutância em situar os sujeitos em termos de teorias tradicionais de hierarquia. Os estudos rotineiramente usam categorias de raça, gênero e classe para distinguir indivíduos particulares, identificar desigualdades e desvantagens ou comentar as contribuições do direito para apoiar ou desafiar a Justiça. Mas muito raramente tais categorias se desenvolvem independentemente, como ferramentas acadêmicas para analisar hierarquias institucionalizadas nas relações entre os sujeitos. Neste campo, os estudos interpretativistas contemporâneos tendem a abandonar o rico e longo legado da análise estruturalista, salvo exceções, como Engel e Munger (2003), que analisam os direitos de inclusão.

O reconhecimento dessas falhas e sua pronta correção não dariam combustível teórico e político para discussões sobre dominação, violência e hegemonia, incentivando movimentos e pessoas a conhecer mais a fundo os entendimentos e usos do direito de seus adversários? Esses ajustes não tornariam as abordagens mais cientes do entorno dos sujeitos, das possibilidades e dos constrangimentos de cada contexto? Enfim, por meio desse roteiro de análise, seria possível realizar uma síntese teórica que tivesse impacto político no atual cenário de crise de direitos? 


\section{Considerações finais}

Antes de perguntar sobre a crítica necessária e a crítica possível da mobilização do direito, talvez compense nos ater um pouco mais sobre o significado de cada uma dessas críticas. Se a crítica necessária pressupõe um questionamento teórico aprofundado do direito liberal, os estudos culturalistas satisfazem tal requisito, uma vez que são capazes de ver no visível a dominação invisível, questionando o avanço do direito para esferas normalmente não tidas como jurídicas. É certo que esses estudos não alcançaram (ainda) uma síntese teórica, mas também não se pode negar os ganhos que trouxeram ao abordar o direito para além das instâncias oficiais, avaliando as construções e violações de direitos em esferas antes menosprezadas.

Além disso, a avaliação do que é necessário, no sentido do que não podemos deixar de tratar, aponta também (embora não somente) para temas específicos e locais, mas que apa116 recem crescentemente nas grandes políticas estatais, como questões relacionadas a políticas identitárias, embates ideológicos nas escolas e universidades, divergências de visões históricas sobre eventos específicos, violência doméstica contra a mulher, vocabulário racista, sexista, xenófobo, homofóbico etc. Atualmente, tratar de grandes teorias e ao mesmo tempo falar de questões locais e específicas é quase impossível.

Porém, o ponto em que os revisionistas talvez tenham razão diz respeito à crítica possível. Se esta pressupõe uma capacidade de interferência nas políticas de direitos do Estado, hoje é difícil enxergar exemplos de que ela esteja acontecendo. O que vemos é uma influência indireta das análises culturalistas sobre movimentos e grupos sociais, que por sua vez têm pressionado o Estado por políticas de direitos ou, mais propriamente, pela defesa de direitos já conquistados, dado o grau das crises políticas e do desmonte a que assistimos. Nesse cenário, talvez as mudanças propostas por McCann ao reconhecer os limites da abordagem 
culturalista consigam aprofundar a teoria a ponto de se chegar numa síntese que tenha impactos concretos.

\section{Celly Cook Inatomi}

é doutora em Ciência Política pela Unicamp, Pesquisadora Colaboradora do Instituto Nacional de Ciência e Tecnologia para Estudos sobre os Estados Unidos (INCT-Ineu). Coordenadora do Grupo de Estudos em Mobilização do Direito no Centro de Estudos Internacionais e Política Contemporânea do Instituto de Filosofia e Ciências Humanas da Unicamp).

\section{Bibliografia}

ABEL, Richard L. 2010. Law and society: project and practice. Annual Review of Law and Social Science, v. 6, pp. 1-23.

BRIGHAM, John. 1996. The constitution of interests: beyond the politics of rights. New York: New York University Press.

BRIGHAM, John. 1998. The constitution of interests: institutionalism, CLS, and new approaches to sociolegal studies. Yale Journal of Law $\mathcal{E}$ the Humanities, v. 10, n. 2, pp. 421-461.

CALAVITA, Kitty. 2002. Engaged research, "goose bumps", and the roll of the public intellectual. Law E Society Review, v. 36, n. 1, pp. 5-20.

CALAVITA, Kitty. 2010. Invitation to law $\mathcal{E}$ society: an introduction to the study of real law. Chicago: University of Chicago Press.

ENGLE, David M.; MUNGER, Frank W. 2003. Rights of inclusion: law and identity in the life stories of Americans with disabilities. Chicago: University of Chicago Press.

EWICK, Patricia. 1992. Postmodern melancholia. Law $\mathcal{E}^{2}$ Society Review, v. 26, n. 4, pp. 755-764.

EWICK, Patricia; SILBEY, Susan S. 1999. Common knowledge and ideological critique: the significance of knowing that the "haves" come out ahead. Law EF Society Review, v. 33, n. 4, pp. 1025-1041.

FISHER III, William W.; HORWITZ, Morton J; REED, Thomas A. (ed.). 1993. American legal realism. New York: Oxford University Press.

FRIEDMAN, Lawrence M. 1986. The law and society movement. Stanford Law Review, v. 38, n. 3, pp. 763-780.

GARTH, Bryant; STERLING, Joyce. 1998. From legal realism to law and society: reshaping law for the last stages of the social activist state. Law E Society Review, v. 32, n. 2, pp. 409-472. 
GEERTZ, Clifford. 1964. Ideology as a cultural system. In: APTER, David E. (ed.). Ideology and discontent. New York: Free Press, pp. 47-76.

GEERTZ, Clifford. 2014. O saber local: novos ensaios em antropologia interpretativa. Petrópolis: Vozes.

GEERTZ, Clifford. 2017. A ideologia como sistema cultural. In: GEERTZ, Clifford. A interpretação das culturas. Rio de Janeiro: LTC.

GORDON, Robert W. 1984. Critical legal histories. Stanford Law Review, v. 36, pp. 56-125.

HANDLER, Joel F. 1992. Postmodernism, protest, and the new social movements. Law E Society Review, v. 26, n. 4, pp. 697-731.

HARRINGTON, Christine B.; YNGVESSON, Barbara. 1990. Interpretive sociolegal research. Law EF Social Inquiry, v. 15, n. 1, pp. 135-148.

HUNT, Alan. 1990. Rights and social movements: counter-hegemonic strategies. Journal of Law and Society, v. 17, n. 3, pp. 309-328.

INATOMI, Celly Cook. 2018. A abordagem da mobilização do direito $e$ as possibilidades de uma pesquisa crítica. Paper apresentando no XI Encontro da Associação Brasileira de Ciência Política, Curitiba, 31 jul. a 3 ago.

KLARE, Karl. 1979. Law-making as praxis. Telos, n. 40, pp. 123-135.

LEVINE, Felice J. 1990. Goose bumps and "The Search for Signs of Intelligent Life" in sociolegal studies: after twenty-five years. Law $\mathcal{E}$ Society Review, v. 24, n. 1, pp. 7-33.

LIU, Sida. 2015. Law's social forms: a powerless approach to the sociology of law. Law $\mathcal{E}^{2}$ Social Inquiry, v. 4, n. 1, pp. 1-28.

MACAULAY, Stewart. 1987. Images of law in everyday life: the lessons of school, entertainment, and spectator sports. Law E Society Review, v. 21, n. 2, pp. 185-218.

MCCANN, Michael. 1996. Causal versus constitutive explanations (or On the difficulty of being so positive). Law $\mathcal{E}$ Society Inquiry, v. 12, n. 2, pp. 457-482.

MCCANN, Michael. 2006. On legal rights consciouness: a challeging analytical tradition. In: FLEURY-STEINER, Benjamin; NIELSEN, Laura Beth. The new civil rigths research: a constitutive approach. Aldershot: Ashgate. pp. ix-xxix.

MERRY, Sally Engle. 1995. Resistance and the cultural power of law. Law Ẽ Society Review, v. 29, n. 1, pp. 11-26.

MUNGER, Frank. 2001. Inquiry and activism in law and society. Law $\mathcal{E}$ Society Review, v. 35, n. 1, pp. 7-20.

MYRDAL, Gunnar. 1944. An American dilemma: the negro problem and modern democracy. New York: Harper and Brothers. 
ROSENBERG, Gerald N. 1996. Review: positivism, interpretivism, and the study of law. Law $\mathcal{E}^{2}$ Social Inquiry, v. 21, n. 2, pp. 435-455.

SARAT, Austin; KEARNS, Thomas R. 1991. The fate of law. Ann Arbor: University of Michigan Press. (The Amherst Series in Law, Jurisprudence, and Social Thought).

SARAT, Austin; KEARNS, Thomas R. 1992. Law's violence. Ann Arbor: University of Michigan Press. (The Amherst Series in Law, Jurisprudence, and Social Thought).

SARAT, Austin; KEARNS, Thomas R. 1993. Law in everyday life. Ann Arbor: University of Michigan Press. (The Amherst Series in Law, Jurisprudence, and Social Thought).

SAVELSBERG, Joachim J. et al. 2016. Discussion Law \& Society Review at fifty: a debate on the future of publishing by the Law \& Society Association. Law E Society Review, v. 50, n. 4, pp. 1017-1036.

SCHEINGOLD, Stuart A. 2004. The politics of rights: lawyers, public policy, and political change. Ann Arbor: University of Michigan Press.

SCHWARTZ, Richard D. 1968. From the editor. Law E Society Review, v. 3, n. 1, pp. 3-6.

SILBEY, Susan S. 2005. After legal consciousness. Annual Review of Law and Social Science, v. 1, pp. 323-368.

SILBEY, Susan S.; SARAT, Austin. 1987. Critical traditions in law and society research. Law E Society Review, v. 21, n. 1, pp. 165-174. 


\section{A ABORDAGEM DA MOBILIZACC̃OO DO DIREITO ENTRE A CRÍTICA NECESSÁRIA E A CRÍTICA POSSÍVEL}

\section{CELLY COOK INATOMI}

Resumo: Este artigo objetiva definir se a crítica proposta pela abordagem da mobilização do direito é uma crítica necessária ao direito liberal ou uma crítica possível, que tenta influenciá-lo. Analisamos a chamada "virada cultural e interpretativista” das análises sociojurídicas dos anos 1980, que exerceu grande influência sobre a mobilização do direito, desenvolvendo uma crítica importante ao direito liberal ao apontar problemas teóricos relevantes para entender os processos de construção e violação de direitos na vida diária. Teoricamente, esses trabalhos demonstraram a importância de questões que permaneciam invisíveis nas visíveis relações pessoais do dia a dia, colocando temas como a dominação, a coerção e a hegemonia do direito em outro patamar. Politicamente, embora tenham se mostrado afastados das políticas de direitos do Estado, influenciaram movimentos sociais, que por sua vez pressionam o Estado por mudanças.

Palavras-chave: Mobilização do Direito; Culturalismo; Crítica do Direito; Política de Direitos.

\section{THE MOBILIZATION OF LAW APPROACH BETWEEN THE NECESSARY AND THE POSSIBLE CRITICAL REVIEW}

Abstract: This paper aims to discuss if the critical review proposed by the mobilization of law approach is necessary to the liberal law, or whether it is a possible critical review, which attempts to influence that law. We analyze the so-called "cultural and interpretive turn" of socio-legal studies in the 1980s, which had a major influence on the mobilization of law, developing a relevant critical review to the liberal law, raising theoretical issues to understanding processes of establishment and violation of rights in everyday life. Theoretically, these studies have 
demonstrated the importance of issues that kept invisible in visible and concrete everyday personal relationships, raising the debate on topics such as domination, coercion and hegemony of law to a higher level. Although they have kept away from governments' politics of rights, these studies can still politically influence social movements that end up pushing the State for change.

Keywords: Mobilization of Law; Culturalism; Critical Review of Law; Politics of Rights.

Recebido: 01/04/2019 Aprovado: 15/10/2019 